In: ISMÉRIO, Clarisse (Org.). Patrimônio Cultural: simbolismos, intertextualidades e polifonias [livro eletrônico]. São Paulo: Vecher, 2021. Disponível em: <https://doi.org/10.47585/9786599324215>.

\title{
Faculdade de Ciências Econômicas: origem do ensino superior em Bagé
}

\author{
Marilene Silveira ${ }^{1}$, Clarisse Ismério ${ }^{2}$ e Elis Dias ${ }^{3}$
}

doi.org/10.47585/9786599324215.5

A criação da Faculdade de Ciências Econômicas inicia o ensino superior em Bagé. E diante de sua importância histórica, objetivamos narrar como ocorreu esse processo. Para tanto, primeiramente apresentamos um breve relato da história econômica de Bagé. E, posteriormente, mostramos, a partir de fontes documentais institucionais, como ocorreu a implantação da Faculdade de Ciências Econômicas e seus desdobramentos. Assim, podemos concluir, a partir das evidências, que as origens do ensino superior em Bagé estão ligadas à necessidade de achar alternativas para o desenvolvimento da região. Investir na formação da juventude era vislumbrar um futuro próspero para o município.

Palavras-chave: Desenvolvimento; Ensino Superior; História.

\footnotetext{
1 Economista, Mestre em Integração e Cooperação Internacional, Professora do Centro Universitário da Região da Campanha - Urcamp, http://lattes.cnpq.br/7704090467284530, e-mail: marilenesilveira@urcamp.edu.br. 2 Historiadora, Doutora em História do Brasil pela PUC-RS. Professora e Pesquisadora do Centro Universitário da Região da Campanha - Urcamp, http://lattes.cnpq.br/4600253785089001, e-mail: clarisseismerio@urcamp.edu.br. 3 Bacharel em Ciências Contábeis. Pesquisadora institucional, http://lattes.cnpq.br/0704143961855179, e-mail: elisdias@urcamp.edu.br.
} 


\section{Introdução}

As histórias das instituições de ensino normalmente estão ligadas ao processo de desenvolvimento da região e às necessidades de formação da comunidade local, assim passam a se caracterizar como Patrimônio Cultural da sociedade. E uma dessas instituições patrimoniais é o Centro Universitário da Região da Campanha - Urcamp, instituição comunitária de ensino superior, cuja história inicia-se com a criação da Faculdade de Ciências Econômicas, em 19 de novembro de 1953.

Considerando que o Patrimônio Cultural se constitui como "um documento vivo do passado que está em constante processo de transformação, tanto pelo envelhecimento causado pelo tempo, como pela ação de grupos sociais" (ISMÉRIO, 2015, p. 26), pretendemos em breves páginas, contar um pouco da trajetória do início do ensino superior na região, a partir da história da Faculdade de Ciências Econômicas, seus desdobramentos, extensões e a sua importância na formação de profissionais.

\section{Bagé: história e perfil econômico}

O município de Bagé $^{4}$ localiza-se na região da Campanha ${ }^{5}$ Meridional, uma das microrregiões do Rio Grande do Sul, que também é formada pelos municípios de Aceguá, Candiota, Dom Pedrito, Hulha Negra e Lavras do Sul. O histórico desta região foi marcado por disputas militares, guerra, acordos diplomáticos e principalmente por abastecer com alimentos e bens as demais regiões. (ISMÉRIO; MEIRA e DRUMM, 2017, p. 37-38)

A base econômica era centralizada na pecuária bovina, que com o tempo cresceu, sendo que entre os anos de 1831 a 1859 "a região da Campanha detinha a parcela mais significativa da produção pecuária que enviava a matéria-prima para as charqueadas localizadas mais a Leste, em Pelotas, e sobre as margens rio Jacuí" (FARINATTI, 2006, p.139).

Bagé alcançou seu apogeu econômico no final do século XIX e início do século XX. Entre os anos de 1891 a 1940, existiam cinco charqueadas de grande porte em plena atividade: a Companhia de Industrial Bageense, Santa Thereza, São Martin, Santo Antônio e São Domingos (BOUCINHAS, 1993). As charqueadas deste período diferenciavam-se das demais de base

\footnotetext{
4 Seguindo esse perfil, o município de Bagé surge como resultado de um acampamento militar comandado por Dom Diogo de Souza, "oficial português encarregado de preservar esta região para a Coroa Portuguesa, concentrou seu exército na fronteira, próximo ao Cerro de Bagé. Antes de partir em direção a Montevidéu, fundou Bagé, deixando grande número de pessoas que não puderam acompanhá-lo, surgindo desse acampamento militar os primeiros arranchamentos. A povoação foi aumentando devagar, espalhando-se ao redor da Praça da Matriz, onde seria o centro do acampamento. Em 1820, foi construída uma igreja para abrigar a imagem de São Sebastião, padroeiro da cidade (VAZ, 2010, p.23). No ano de 1846, tornou-se freguesia e, em 1859, por Lei da Província, Bagé foi elevada à esfera de cidade (FAGUNDES, 2012).

5 Sergio da Costa Franco destaca que o termo campanha no vocabulário rio-grandense refere-se às "áreas rurais" ou "zona fora da cidade e vilas", mas, de acordo com as suas características naturais físicas, é definida como "[...] região sudoeste, desde o Uruguai até Bagé caracterizada pela topografia singela, de planícies e coxilhas baixas, por uma vegetação de campinas rasas." (FRANCO, 1969, p. 65).
} 
escravista por possuírem mão de obra assalariada, por utilizar de maquinário, possuírem condições sanitárias e aprimoramento técnico. Dinamizando o processo de escoamento da produção, existia a rede ferroviária que ligava Bagé ao porto de Rio Grande (SOARES, 2006).

A Companhia de Industrial Bageense, fundada em 1891, foi a primeira charqueada de grande escala, e além do charque "produzia graxa comestível, línguas em conserva e toucinho enfumaçado, como evidenciam os anúncios publicados no jornal O Comércio, além de produzir, provavelmente, velas, sabão e couros." (BOUCINHAS, 1993, p. 31).

Destaca-se, em 1897, a fundação da Charqueada de Santa Thereza, segunda de grande escala, fundada por Antônio Nunes de Ribeiro Magalhães, considerada um símbolo da modernização para o período. E conforme salienta Lemieszek (1997), o desenvolvimento das charqueadas proporcionou melhorias no município, tais como a luz elétrica, telefone, cinema, automóvel e feiras de exposição.

O "ciclo de ouro" das Charqueadas de Bagé se encerra com o advento dos frigoríficos, iniciando em 1940 com a Sociedade Industrial de Subprodutos Animais Ltda - SISPAL. E no decorrer dos anos 1940 e 1950, a economia da região passa por um processo de declínio decorrente da:

[...] queda da rentabilidade dos campos, o que levou à descapitalização dos produtores, à diminuição de investimentos. O gado era comercializado com os frigoríficos estrangeiros que mantinham seu preço baixo [...]. A partir de 1950, os frigoríficos gaúchos de capital americano Swift, Armour e Cia passaram a enfrentar a concorrência de frigoríficos do interior paulista, de Minas Gerais, do norte do Paraná e Mato Grosso, que usufruíam de ampla oferta de crédito do Governo Federal e de seus Governos Estaduais. (PREFEIRURA MUNICIPAL DE BAGÉ, 2011, p. 64).

A alternativa encontrada para sair desse quadro foi criar instituições de ensino superior locais, para investir na formação intelectual e capacitação profissional de jovens que, por conseguinte, iriam promover o desenvolvimento de Bagé e região.

\section{As origens do Ensino Superior em Bagé}

A industrialização brasileira passou por um processo de ascensão na segunda metade da década de 1950, impulsionada pelos investimentos diretos do Estado ou de empresas estatais em indústrias de base (CAPUTO e MELO, 2009).

Eessa característica se reflete na política educacional brasileira do período, que foi marcada pelo "nacionalismo e trabalhismo" de Getúlio Vargas e na proposta de "educação para o desenvolvimento" de Jucelino Kubitschek, alicerçada no perfil técnico-profissionalizante, cuja educação para o trabalho iniciaria nos anos primários e no ensino médio ocorreria o processo de profissionalização. Com a preocupação que a escola atendesse o mercado de trabalho, passa a beneficiar, entre 1957 e 1959, o ensino industrial com recursos financeiros, deixando a universidade para aqueles que tivessem “vocação intelectual” (GUIRALDELLI JR., 2003, p. 112-113).

Porém, o entusiasmo pelo crescimento econômico, promovido pelo governo Kubitschek, 
chegou ao ensino superior, em decorrência do alto índice alunos matriculados no ensino médio, de tal forma que contava ao "final da década de 1950 com 21 universidades e mais de cem instituições de ensino superior." (ROSSATO, 2005, p. 144).

Foi exatamente nesse período, e com o perfil profissionalizante, que inicia o ensino superior em Bagé, com a fundação da Faculdade de Ciências Econômicas, em 19 de novembro de 1953, pela Associação de Cultura Técnica e Econômica - ABCTE, cujos objetivos eram: "Ministrar, em seu aspecto superior, o ensino de Ciências Econômicas; Promover e facilitar a prática da investigação no ramo econômico, social, comercial e administrativo.” (PDI, 2014-2019, p. 20). Tais objetivos pretendiam dar conta da necessidade da formação dos futuros profissionais e empreendedores locais, que propiciassem o desenvolvimento da região baseado no "aumento do fluxo de renda real, isto é, incremento na quantidade de bens e serviços por unidade de tempo à disposição de determinada coletividade" (FURTADO, 1961, p.115-116).

Em $1955^{6}$, foi autorizado o funcionamento da Faculdade de Ciências Econômicas, que teve como primeiro diretor ${ }^{7}$ o Dr. João Lira de Farias e como docentes:

Darcy Quintana, Eduardo Contreiras Rodrigues, João Coronel Sais, Antenor Gonçalves Pereira e João Lyra de Farias, que deverão lecionar na primeira série. José Ferreira, Hermenegildo Machado, Bruno Petry e Oswaldo Costa Moraes, professores da 2a série. Clovis Bevilaqua Sobrinho, Carlos Resende Lopes, Mario Torres, Paulo Thompson Flores, Jayme da Silva Tavares e Telmo Candiota da Rosa, da $3^{\text {a }}$ série. Nairo Codevilla, Moacyr Borges da Silveira, Justino da Costa Quintana, João Didonet Neto, Lígia Almeida Gonçalves e Elida Rodrigues da Costa, professores da $4^{\text {a }}$ série. (Ata número I, 03 de abril de 1955, p. 1).

$\mathrm{Na}$ mesma ata, ficou determinada a abertura do exame vestibular, que ocorreria do dia 20 a o dia 23 de abril de 1955. Observamos que, nesse período, os cursos superiores eram organizados em anos, vindo a ser alterado com a Reforma Universitária de 1968 (Lei 5.540/68), na qual a matrícula passou a ser por disciplina e semestre, visando maior flexibilidade na composição curricular.

No Diário Oficial de 23 de maio de 1957, foi publicado o Decreto nº 41.559, de 22 de maio de 1957, que reconhecia o Curso de Ciências Econômicas da Faculdade de Ciências Econômicas de Bagé (Figura 1).

\footnotetext{
6 No mesmo ano, também é fundada a Faculdade Católica de Filosofia, Ciências e Letras de Bagé , como extensão da Universidade Católica de Pelotas - UCPel, com o apoio do reitor em exercício, bispo Dom Antônio Záttera, que "atendendo às grandes necessidades de formação intelectual e moral da juventude da cidade de Bagé, com uma população escolar já muito elevada, contando com 9 estabelecimentos de ensino secundário e uma Escola Superior; Considerando a necessidade de formar seu próprio professorado secundário para atender mais facilmente aos mencionados estabelecimentos. Decreto do Gabinete Episcopal, 27 de maio de 1957. In: AZEVEDO, ISMÉRIO e SILVEIRA, 2006, p. 278.

7 Ao longo dos anos, também foram diretores: João Lira (04/58 - 09/58); Telmo Candiota da Rosa (10/58 - 01/67); Roberto Nocchi Cachapuz (03/68 - 12/87); José Trombini (12/87 - 02/88); e Enio Del Geloso Nocchi (03/88 - 06/2010).
} 
Figura 1: Decreto de reconhecimento publicado no Diário Oficial de 23 de maio de 1957.

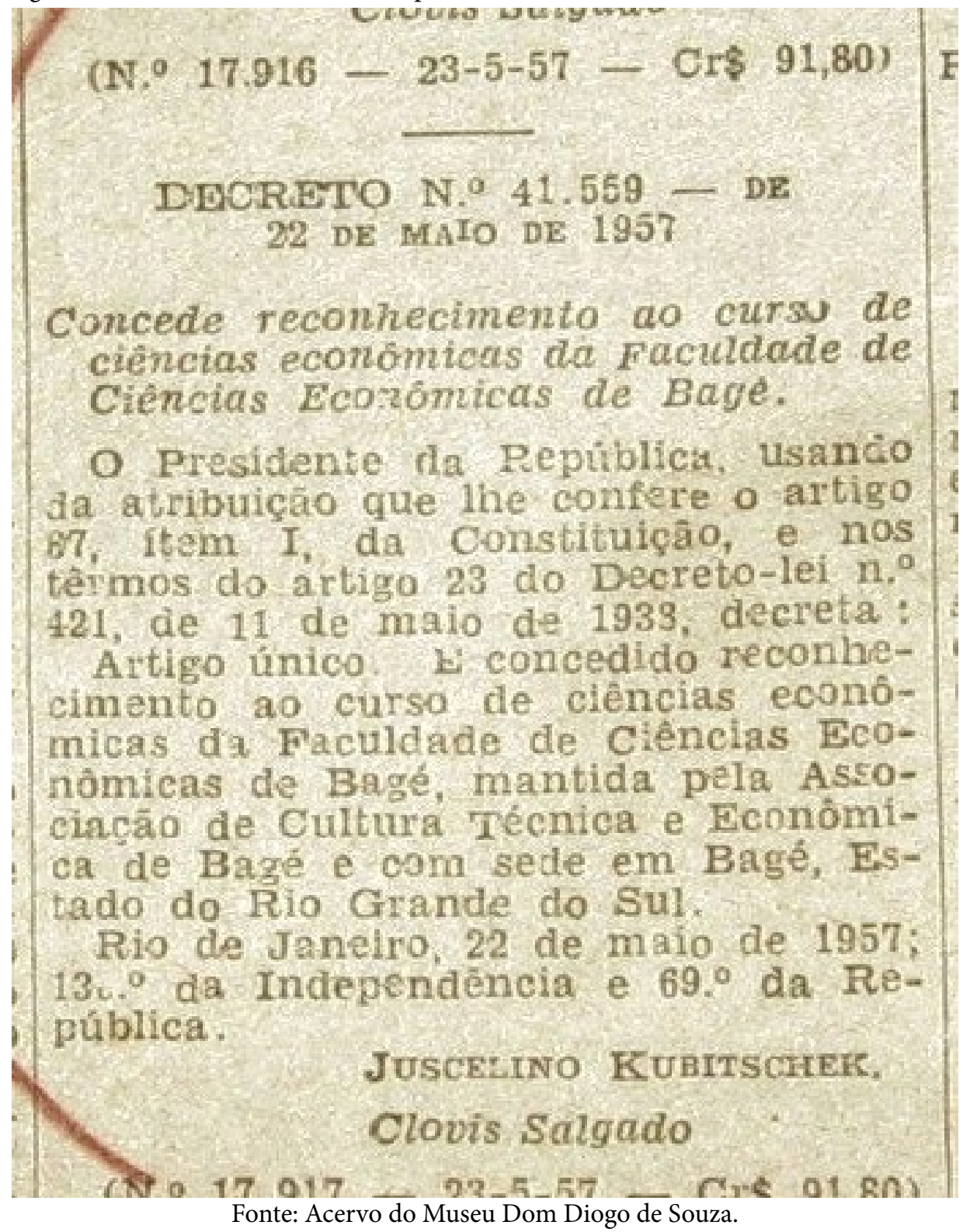

A primeira turma de Bacharéis em Ciências Econômicas formou-se em 1958 (Figura 2). Desse grupo, alguns nomes de destaque como Terêncio L. Pereira, natural de Bagé, após formado, abriu um Escritório de Contabilidade e Assessoria Financeira, muito respeitado na cidade; Nadyr Quintana, também natural de Bagé, após formado passou a lecionar no Curso de Ciências Econômicas e tinha um cargo de assessor financeiro junto à faculdade; José Dagoberto Pereira, natural de Jaguarão, após formado, atuou na parte financeira do Frigorífico São Domingos, foi professor de Matemática no Curso de Ciências Econômicas, docente no Científico e assessor do Pró-Reitor de Administração da FUnBa; Jonatas J. R. Torales, natural de Pinheiro Machado, escriturário do Banco do Brasil e professor de Lógica no Curso de Ciências Econômicas da FUnBa; Augusto Pinheiro Grande, natural de Araxá, Minas Gerais, militar, após formado iniciou com um Escritório de Contabilidade, com destaque em Bagé, e foi professor de Contabilidade no Curso de Ciências Econômicas. 
Figura 2: 1ª Turma de Bacharéis em Ciências Econômicas.

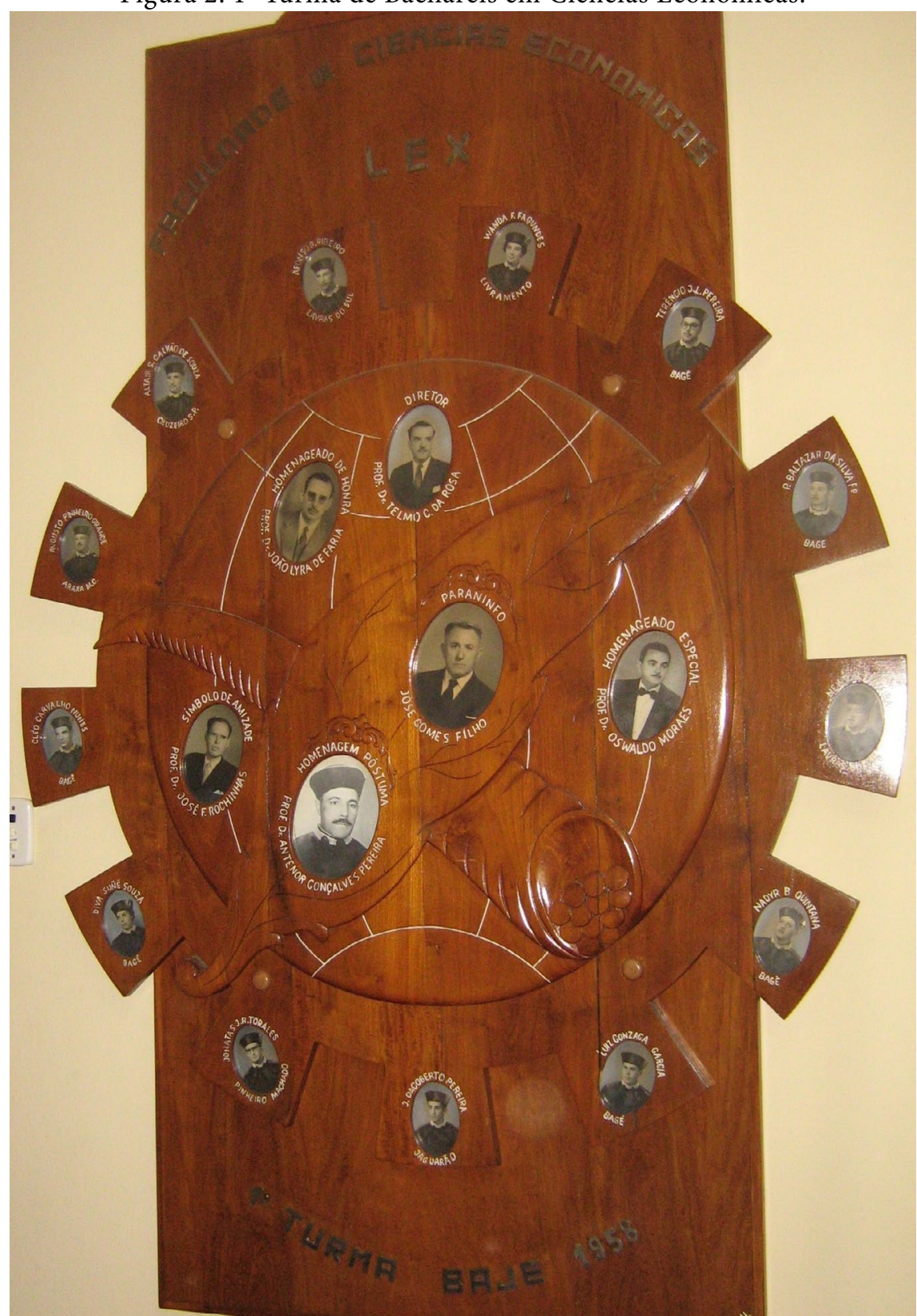

Fonte: Acervo do Museu Dom Diogo de Souza.

Os economistas da época poderiam abrir escritórios de contabilidade e atuar como contadores. Após a implementação da LDB de 1968 foram instituído os Curso de Ciências Contábeis e Técnico em Contabilidade.

Em 1969, foi criada a Fundação Universidade de Bagé - FUB, que posteriormente se transformaria em Fundação Attila Taborda - FAT ${ }^{8}$, que passou a manter todos os cursos superiores das Faculdades de Ciências Econômicas.

Em agosto de 1970, conforme a Ata nº. 36 do Conselho Universitário - Universidade

8 A denominação da entidade mantenedora teve que ser alterada por ser considerada indevida a expressão "universidade", sendo aprovada como Fundação Attila Taborda. (Proc. No 1.146/72 - CFE). 
Católica de Pelotas, o presidente da Fundação Universidade de Bagé, Dr. Attila Taborda ${ }^{9}$, solicitou que a Faculdade de Ciências Econômicas e a Faculdade de Belas Artes, mantidas pela FUB, fossem agregados à UCPel, "visado por esse pedido de agregação é a adequação jurídica da Fundação Universidade de Bagé às exigências do Ministério de Educação e Cultura, em preparação à criação da futura Universidade de Bagé”. Nesse mesmo documento, consta o pedido para criação dos cursos de Ciências Contábeis e Ciências Administrativas ${ }^{10}$, também agregados à UCPel. (AZEVEDO, ISMÉRIO e SILVEIRA, 2006, p. 180-181)

Em 1986, foi aprovado pelo Conselho Federal de Educação o projeto de transformação das Faculdades Unidas de Bagé - FUnBa em universidade, sendo reconhecida como Universidade da Região da Campanha, pela portaria ministerial no 52, de 16 de fevereiro de 1989 . Nesse período, a instituição cresceu tornando-se multicamp ${ }^{11}$.

No ano de 1990, adequando-se às novas estruturas institucionais, foi criado o Centro de Ciências da Economia e Informática - CCEI pelo estatuto da Universidade da Região da Campanha, aprovado pelo parecer CNE/CES n 30/2002; Portaria MEC n 1481, de 15/05/2002, composto pelos Cursos de Administração, Ciências Contábeis e Informática, tendo como objetivo "buscar o desenvolvimento constante de seus professores e secretárias e incentivar trabalhos científicos voltados para sua realidade e para o desenvolvimento da região em que está inserida".

9 Attila Taborda nasceu em Caçapava do Sul, em 1897, e faleceu em Bagé, em 1975. Com a morte de seu pai, em 1907 veio morar em Bagé com a mãe e os irmãos. Casou-se com Julinha Peixoto Costa, em 1923, que faleceu em 1944. Em 1947, contraiu um segundo matrimônio com Laura Lins Vernet. No ano de 1937, iniciou o Curso de Medicina, na Escola Médico-Cirúrgica do Rio Grande do Sul, formando-se em 1942. Taborda recebeu da Santa Sé, representada na figura do Papa Pio XII, em 1957 a comenda de "Cavaleiro da Ordem Equestre de São Silvestre”, distinção honorífica concedida pelos serviços prestados à causa da Igreja Católica. Em 1960, tornou-se diretor da Faculdade Católica de Filosofia, Ciências e Letras. E 1969, institui por escritura a Fundação Universidade de Bagé. Em 1970, torna-se presidente da Fundação Universidade de Bagé e, em 1972, foi empossado como Pró-reitor das Faculdades Unidas de Bagé, agregada à Universidade Católica de Pelotas. (LOPES, 1970, p. 1 e AZEVEDO, ISMÉRIO e SILVEIRA, 2006, p. 280 e 282).

10 Também consta na ata o pedido de criação dos Cursos de Engenharia Operacional Rural, Biblioteconomia e Ciências Biológicas. Posteriormente foram autorizadas as Faculdades de Direito e Educação Física. Em 1976, os Cursos de Agronomia e Medicina Veterinária, que foram criados como extensão da Universidade Federal de Santa Maria - UFSM, passaram a ser responsabilidade da Fundação.

11 Conforme o relato histórico presente no Plano de Desenvolvimento Institucional da Urcamp, publicado em matéria especial do Jornal Minuano: “o campus aproximado de Caçapava do Sul, existente anterior à transformação da instituição em universidade multicampi, passou a ser campus da universidade, com o desenvolvimento de um planejamento global de suas atividades, sendo as infraestruturas físicas, cedidas pela Prefeitura Municipal e Governo Estadual. O campus aproximado de Dom Pedrito passou a ser campus da universidade, conforme Portaria Ministerial 52/89 de 16 de fevereiro de 1989, sendo a infraestrutura física cedidas pela Prefeitura Municipal e Governo Estadual. Em 1985, houve a inserção da ASPES à Urcamp, passando a mesma a ser um campus universitário da Urcamp. Em 19 de outubro de 1989, foi celebrado o convênio entre a Fundação Attila Taborda - FAT e sua mantida Universidade da Região da Campanha - URCAMP e a Fundação Educacional de São Gabriel - FESG, visando a transferência dos cursos superiores das Faculdades Integradas de São Gabriel para a Urcamp, com o propósito de racionalizar e expandir o ensino superior na região, promovendo a adequação entre os cursos e vagas oferecidas, a demanda regional, e o desenvolvimento das comunidades inerentes à sua área de influência. O campus universitário de Alegrete, instalado no dia 6 de dezembro de 1996, conforme Portaria MEC n 1143 de 7 de novembro de 1996, na Fronteira Oeste do Estado, constitui-se em mais uma unidade da Universidade da Região da Campanha. A incorporação dos cursos superiores da Faculdade de Filosofia, Ciências e Letras de São Borja, pela Urcamp, ocorreu através da Portaria MEC no 1148 de 07/11/1996. Nos anos de 2000 a 2011, com a aprovação do funcionamento do Curso de Ciências Contábeis - Bacharelado, a Portaria MEC no 346 de 23/02/2001 cria o campus universitário de Itaqui da Universidade da Região da Campanha”. (RIBEIRO, Chrystian. A Universidade e sua formação. Jornal Minuano, 25 de maio de 2015, p. 14). 
Uma das ações foi a criação, em outubro de 1997, da Revista do CCEI, cuja missão era a proposta de a revista divulgar a pesquisa e o conhecimento científicos nas áreas de Administração, Ciências Contábeis, Economia, Informática (Sistemas de Informação) e demais áreas correlatas. Foi idealizada por Luiz Cláudio Dalmolin, que atuou como editor-chefe do periódico até março de 2004. As edições impressas foram produzidas até 2013 e em 2014 passou para o modelo digital, através da plataforma OJS (Open Journal Systems). Nesses anos, foram responsáveis pela editoria da revista Lóren Pinto Gonçalves, Marilene Vaz Silveira, Clarisse Ismério, Fábio Josende Paz e, atualmente, Henry Gomes de Carvalho.

Visando o aprimoramento do acadêmico em sua prática profissional voltada para pesquisa e extensão, em diversas áreas do conhecimento, foi criada, em abril de 2004, a Consultoria Júnior da Urcamp.

A Consultoria Jr. é um espaço que permite aos estudantes o desenvolvimento profissional através de trabalhos realizados com flexibilidade e inovação junto aos mercados em que a universidade atua e onde os acadêmicos deverão atuar no futuro. O projeto gera oportunidades de aprimoramento mediante atividades de extensão e pesquisa nas diversas áreas do conhecimento, promove o desenvolvimento de senso de responsabilidade e espírito empreendedor, bem como as potencialidades individuais, facilitando o ingresso no mercado de trabalho ${ }^{12}$.

No final dos anos 1980 e início dos 1990, em decorrência da globalização e dos novos processos econômicos, o conceito de desenvolvimento regional passa a ser entendido como:

[...] um processo complexo de mudanças e transformações de ordem econômica, política e, principalmente, humana e social. Desenvolvimento nada mais é que o crescimento - incrementos positivos no produto e na renda - transformado para satisfazer as mais diversificadas necessidades do ser humano, tais como: saúde, educação, habitação, transporte, alimentação, lazer, dentre outras. (OLIVEIRA, 2002, p. 40).

Logo, a formação de qualidade de profissionais competentes é de extrema importância para que ocorra o desenvolvimento, pois tornam-se agentes sociais que atuam transformando a comunidade em que vivem.

Esse pensamento está presente na missão e visão da Urcamp, uma instituição que nasceu para promover o desenvolvimento de Bagé e região.

MISSÃO: Produzir e socializar o conhecimento para a formação de sujeitos socialmente responsáveis que contribuam para o desenvolvimento global.

VISÃO: Ser uma instituição de referência para a comunidade interna e externa, pela participação nas ações dirigidas ao desenvolvimento regional sustentável e seus reflexos na sociedade. (EXTRATO PDI 2018-2020, p. 6).

12 Consultoria Júnior. Disponível em: <https://www.urcamp.edu.br/pesquisa-e extensao/inovacao/ consultoria-junior $>$. Acesso em: 28 dez. 20. 


\section{Considerações finais}

Ao refletirmos sobre a história da Faculdade de Ciências Econômicas, podemos constatar que as origens do ensino superior em Bagé estão ligadas à necessidade de achar alternativas para o desenvolvimento da região. E, principalmente, que foi uma instituição criada para atender aspirações da comunidade local, que buscava um ensino de qualidade para sua juventude, capacitando-os para impulsionar o crescimento econômico.

Essa missão está sendo cumprida, pois ao longo de sessenta e sete anos a Urcamp formou inúmeros profissionais qualificados, bacharéis e licenciados, para atuar no mercado rio-grandense.

Se hoje Bagé é definida como uma cidade universitária, pois nela atuam seis instituições de ensino superior, é graças à ousadia de visionários que lutaram pelo ensino superior local.

\section{Referências}

AZEVEDO, Regina Quintanilha; ISMÉRIO, Clarisse; SILVEIRA, Marilene Vaz. Apontamentos sobre a disciplina História da Educação na Universidade da Região da Campanha - URCAMP (1959-2001). In: História da Educação, ASPHE/FAT/UFPel, Pelotas, n. 19, p. 275-294, abr. 2006. Disponível em: <http//fae.ufpel.edu.br/asphe>.

BOUCINHAS, Cláudio A. A História das Charqueadas de Bagé (1891 - 1940) na literatura. Dissertação (Mestrado em História) - Escola de Humanidades, Pontifícia Universidade Católica do Rio Grande do Sul, Porto Alegre, 1993.

CAPUTO, A. C.; MELO, H. P. A industrialização brasileira nos anos de 1950: uma análise da instrução 113 da SUMOC. Estud. Econ., São Paulo, v. 39, n. 3, p. 513-538, set. 2009. Disponível em: <https://doi.org/10.1590/S0101-41612009000300003>. Acesso em: 25 dez. 2020.

FAGUNDES, Elisabeth Macedo de. Inventário Cultural de Bagé. Um passeio pela história. 2. ed. Porto Alegre: Praça da Matriz/Evangraf, 2012.

FRANCO, Sérgio da Costa. A Campanha. In. Rio grande do Sul Terra e Povo. 2. ed. Porto Alegre: Editora Globo, 1969.

FURTADO, Celso. Desenvolvimento e subdesenvolvimento. Rio de Janeiro: Fundo de Cultura, 1961.

GHIRALDELLI JR., Paulo. Filosofia e História da Educação Brasileira. São Paulo: Manole, 2003.

VAZ, Heron Ungaretti. A formação territorial na Região da Campanha Meridional: a organização socioprodutiva da propriedade familiar no distrito de Palmas - Bagé/RS. Dissertação (Mestrado em Ciências Sociais) - Instituto de Sociologia e Política, Universidade Federal de Pelotas, Pelotas, 2010. 
ISMÉRIO, Clarisse; MEIRA, Eventon e DRUMM, Elisabeth. Caracterização da Região. In: DRUMM, Elisabeth (Org.). Plano Estratégico de Desenvolvimento da Região da Campanha 2015-2030. Bagé, RS: EDIURCAMP, 2017.

ISMÉRIO, Clarisse. Educação patrimonial: promovendo o desenvolvimento regional a partir do patrimônio cultural. In. Ágora, Santa Cruz do Sul, v. 17, n. 2, p. 24-31, maio 2015. Disponível em: $<$ https://online.unisc.br/seer/index.php/agora/article/view/6589/4833>. Acesso em: 23 dez. 2020.

LEMIESZEKI, Cláudio L. Bagé: Relatos de sua história. Porto Alegre: Martins Livreiro, 1997.

LOPES, Mário. Reconhecimento a Atila Taborda: solenidade desta manhã na FUnBa. In: Jornal Correio do Sul, 30 de julho de 1970, p. 1.

OLIVEIRA, Gilson Batista de. Uma discussão sobre o conceito de desenvolvimento. In: Rev. FAE, Curitiba, Ed. Maio/Ago, 2002, p. 34-48. Disponível em: <https://revistafae.fae.edu/revistafae/article/view/477/372>. Acesso 30 de dezembro de 2020.

EXTRATO DO PLANO DE DESENVOLVIMETO INSTITUCIONAL URCAMP 2018-2010. Disponivel: <www. urcamp.edu.br>.

PREFEITURA MUNICIPAL DE BAGÉ. Plano de Desenvolvimento Econômico 2011-2031. Bagé, RS: EDIURCAMP, 2011.

RIBEIRO, Chrystian. A Universidade e sua formação. In: Jornal Minuano, 25 de maio de 2015, p. 14.

ROSSATO, R. Universidade: nove séculos de história. Passo Fundo, RS: UPF, 2005. 